\title{
CIRCULAR REARRANGEMENT INEQUALITY
}

\author{
HAIYANG YU
}

Abstract. This paper presents an analogue of the rearrangement inequality, namely the circular rearrangement inequality. It holds for any finite sequence of real numbers. A volume-invariant packing problem and a combinatorial isoperimetric problem are addressed, as the geometric interpretation of the inequality.

Mathematics subject classification (2010): 26D15, 05D99, 52C99, 90C27.

Keywords and phrases: Rearrangement inequality, circular permutation, geometric interpretation.

\section{REFERENCES}

[1] J. C. Bourin, Reverse rearrangement inequality via matrix technics, J. Inequal. Pure and Appl. Math. 7, 2 (2006), Article 43.

[2] A. BURCHARD, A short course on rearrangement inequalities, Lecture notes, http://www.math.toronto.edu/almut/rearrange.pdf, 2009.

[3] J. W. S. CASSELS, An Introduction to the Geometry of Numbers, Springer-Verlag, Classics in Mathematics, Berlin, 1997.

[4] W. ChAn, Stochastic rearrangement inequalities, J. Multivar. Anal. 23, 2 (1987), 257-275.

[5] P. W. DAY, Rearrangement inequalities, Canad. J. Math. 24 (1972), 930-943.

[6] C. DRAGHICI, Rearrangement inequalities with application to ratios of heat kernels, Potential Anal. 22, 4 (2005), 351-374.

[7] H. HAJAIEJ, Rearrangement inequalities in the discrete setting and some applications, Nonlinear Anal. Theory, Meth. and Appl. 59, 3-4 (2010), 1140-1148.

[8] F. Hamel, N. Nadirashvili, And E. Russ, Rearrangement inequalities and applications to isoperimetric problems for eigenvalues, Ann. Math. 174, 2 (2011), 647-755.

[9] G. H. Hardy, J. E. Littlewood and G. Pólya, Inequalities, Cambridge University Press, International Edition, Cambridge, 1952.

[10] F. Holland, Rearrangement Inequalities, Lecture notes, http://euclid.ucc.ie/pages/ MATHENR/MathEnrichment/rearraniq08.pdf, 2008.

[11] A. W. Marshall, I. Olkin, And B. C. Arnold, Inequalities: Theory of Majorization and Its Applications, Springer, Springer Series in Statistics, New York, 2011.

[12] L. MiRS Ky, On the trace of matrix products, Math. Nachr. 20, 3-6 (1959), 171-174.

[13] M. Newman, Kantorovich's inequality, J. Res. National Bur. Standards 64B (1960), 33-34.

[14] H. RichteR, Zur abschätzung von matrizennormen, Math. Nachr. 18 (1958), 178-187.

[15] F. RiESZ, Sur une inégalité intégrale, J. London Math. Soc. 5 (1930), 162-168.

[16] L. TIE, K. Y. CAI, AND Y. LIN, Rearrangement inequalities for Hermitian matrices, Linear Alg and its Appl 434, 2 (2011), 443-456.

[17] J. VON NEUMANn, Some matrix-inequalities and metrization of matric-space, Tomsk. Univ. Rev. 1 (1937), 286-300. 